\title{
ALL-OPTICAL MODULATION IN GALIIUM ARSENIDE INTEGRATED OPTICAL WAVEGUIDES
}

\author{
G. MCWRIGHT \\ B. ROSS \\ W. GUTHREAU \\ D. LAFAW \\ M. LOWRY \\ W. TINDALL
}

THIS PAPER WAS PREPARED FOR THE

SIXTH MEETING IN ISRAEL ON OPTICAL ENGINEERING

TEL AVIV

DECEMBER 19-21, 1988

JANUARY 27,1988

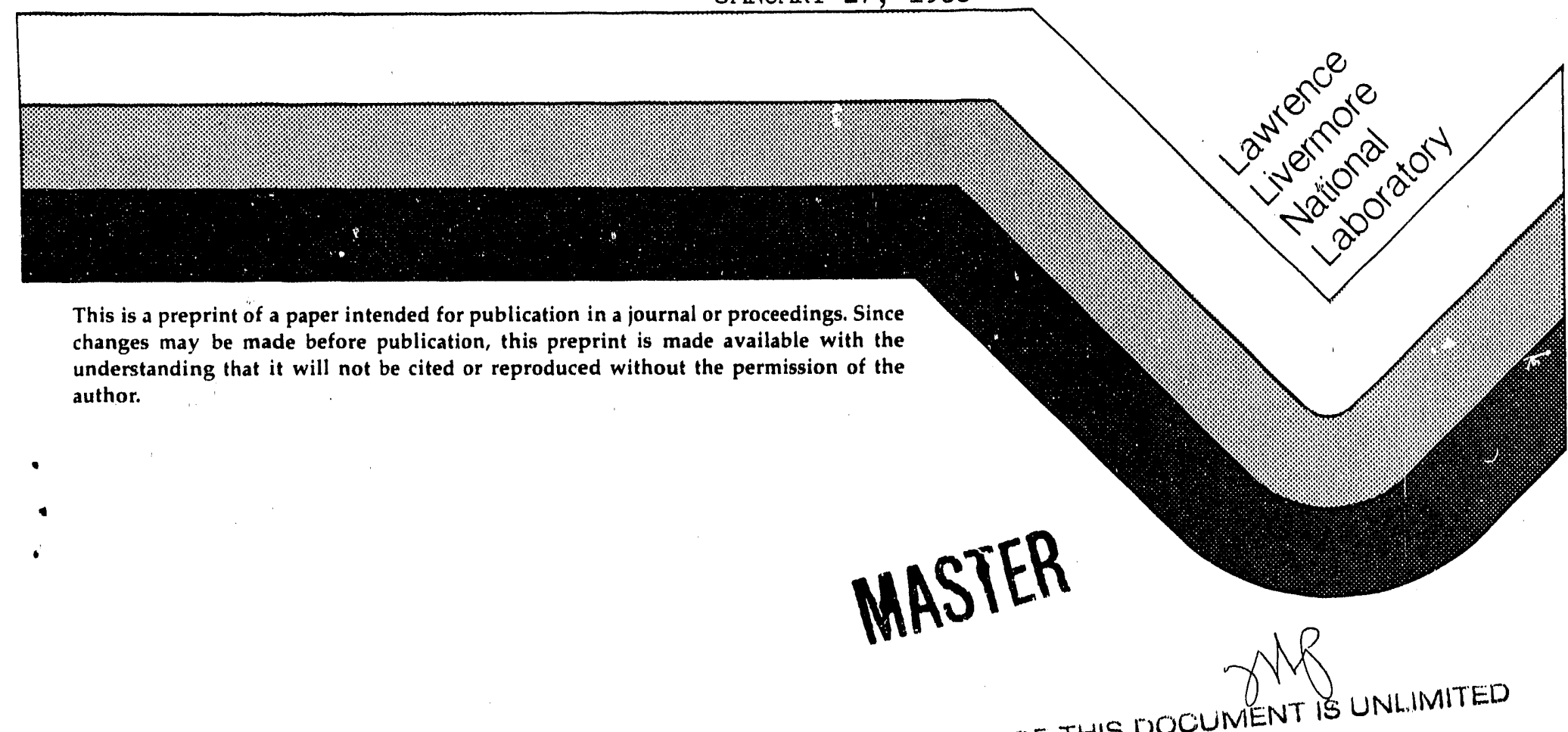

$N$ changes may be made before publication, this preprint is made available with the understanding that it will not be cited or reproduced without the permission of the author. 


\section{DISCIAIMER}

This document was prepared as an account of work sponsored by an agency of the Inited Stutes Government. Neither the United States Government nor the University of Californiu nor any of their employees, makes any warranty, express or implied, or assumes any legal liabiliv or responsibility for the accuracy, completeness, or usefulness of any information, a,oparatus, product, or process disclosed, or represents that Its use would not infringe wrivately owned rights. Reference herein to any specific commercial products, process, or service by trade name, trademark, manufacturer, or othernise, does not necessarily constitute or imply its endorsement, recommendation, or favoring by the Inited States Government or the University of Cullfornia. The views and opinions of authors expressed herein do not necessarily state or reflect those of the Inited States Government or the University of C'alifornia, and shall not be used for advertising or product endorsement purposes. 


\title{
All-Optical Modulation in Gallium Arsenide Integrated Optical Waveguides
}

\author{
G. McWright, B. Ross, W. Guthreau, D. Lafaw, M. Lowry, and W. Tindall \\ Lawrence Livermore National Laboratory \\ Livermore, CA 94550 USA
}

\begin{abstract}
We have investigated all-optical modulators in gallum arsenide integrated optical waveguides; these modulators use electron-hole pair generation to alter the propagation characteristics of a guided light beam.

\section{INTRODUCTION}

All-optical signal processing and routing is one way that vast amounts of information can be efficiently processed. Because two light beams do not interact with each other in a vacuum, the task of building all-optical signal processin' elements can frequently become non-trivial; a nonlinear optical material is generally required so that these light beams can interact indirectly. Researchers have thus investigated many different types of nonlinear optical materials and device configurations to perform such all-optical signal processing functions, including organic polymer thin film waveguides (1), multiple quantum well resonators (2), and bistable optical logic gates (3). Regretfully, such structures generally require exotic material technologies and device configurations. Furthermore, devices such as bistable optical logic gates, which use resonator geometries, tend to be very temperature sensitive. In addition, because exciton lines are very narrow, multiple quantum well based devices require stringent controls on the optical wavelength (with a corresponding increase in optical attenuation if the device is operated at an exciton peak). Because of the above limitations, there has been a resurgence of interest in all-optical modulators which use free carrier injection to modulate a guided beam (in this case, free carrier injection changes both the refractive index and absorption coefficient of a semiconductor material ). For example, Normandin et al. (4) and Colbourne et. al. (5) have each investigated all-optical modulators and logic gates in silicon based integrated optical waveguides at wavelengths of 1.32 and $1.55 \mu \mathrm{m}$. In addition, McFee et. al. described similar work in gallium arsenide integrated optical waveguides, but at a wavelength of $10.6 \mu \mathrm{m}(6)$. Here, we discuss free-carrier modulation in gallium arsenide integrated optical waveguides at a wavelength of $1.3 \mu \mathrm{m}$.
\end{abstract}

\section{EXPERIMENTAL SET-UP}

A schematic of the ridge integrated optical waveguide structure of interest is shown in Fig. 1.

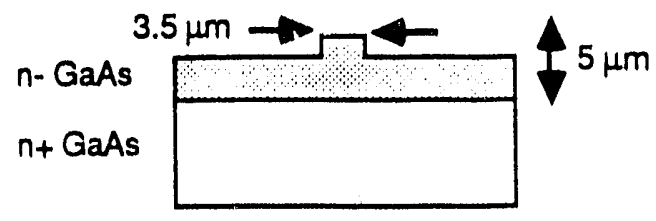

Fig. 1. GaAs ridge optical waveguide.

Layer 1 is a $5 \mu \mathrm{m}$ layer of low doped ( $\mathrm{n}$-) GaAs grown by metal-organic-chemical-vapor-deposition (MOCVD) on a high doped $(\mathrm{n}+)$ GaAs substrain. I ayer 1 has a lower free carrier concentration than the high doped substrate; consequently layer 1 has a higher refractive index, and light is confined to layer 1 . Lateral confinement is provided ' $y$ etching ridges into the surface of layer 1 with a wet chemical mixture, thus "strip-loading" the structure.

Our experimental set-up is shown in Figs. 2a and 2b. A "probe" $1.3 \mu \mathrm{m}$ laser beam is coupled into the GaAs ridge optical waveguide. Subsequently, a "pump" $1.3 \mu \mathrm{m}$ laser beam from an optical fiber at height, $h$, above the surface illuminates the waveguide structure from the top, thereby injecting free carriers into the structure. Injection of free 
carriers increases the absorption coefficiecnt of layer 1 , thus decreasing the amount of $1.3 \mu \mathrm{m}$ laser light transmitted. As a result, the propagation characteristics of the $1.3 \mu \mathrm{m}$ "probe" beam are altered by the "pump" beam.

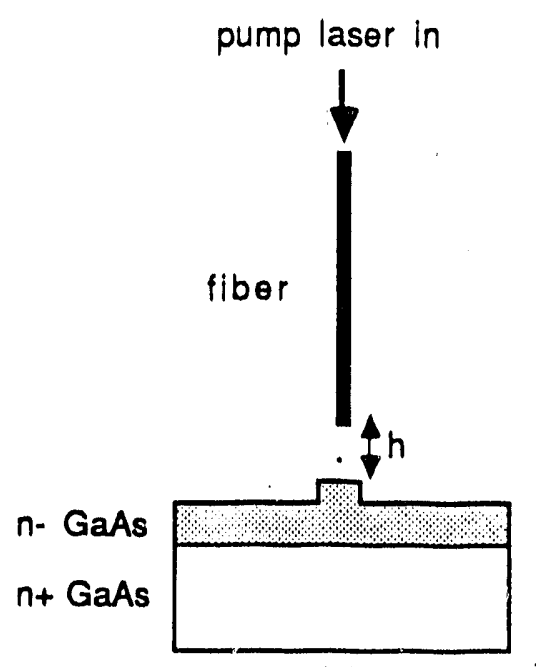

(a)

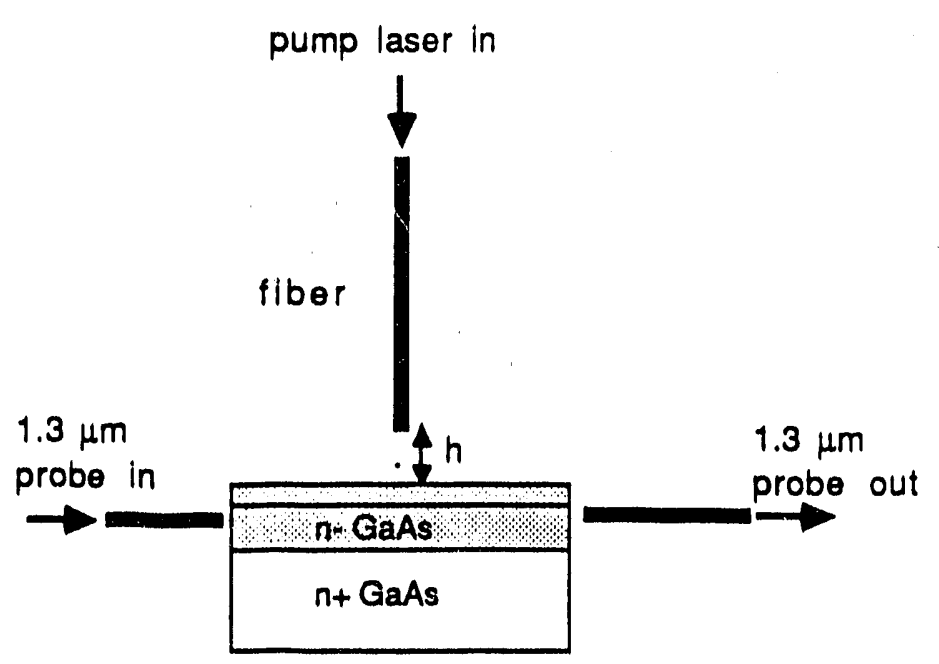

(b)

Figs 2a-b. Front (a) and side (b) view of light-on-light experimental set-up.

\section{EXPERIMENTALRESUITS}

In our first series of experiments, we coupled $1.3 \mu \mathrm{m}$ laser light into a GaAs integrated optical waveguide structure. We then illuminated the integrated optical structure with sub-nanosecond, $30 \mathrm{~nJ}, 0.571 \mu \mathrm{m}$, light pulses from a nitrogen pumped dye laser, and monitored the degradation in transmission of the $1.3 \mu \mathrm{m}$ guided beam with a high speed photodetector. An oscilloscope trace of the photodetector output is shown in Fig. 3.

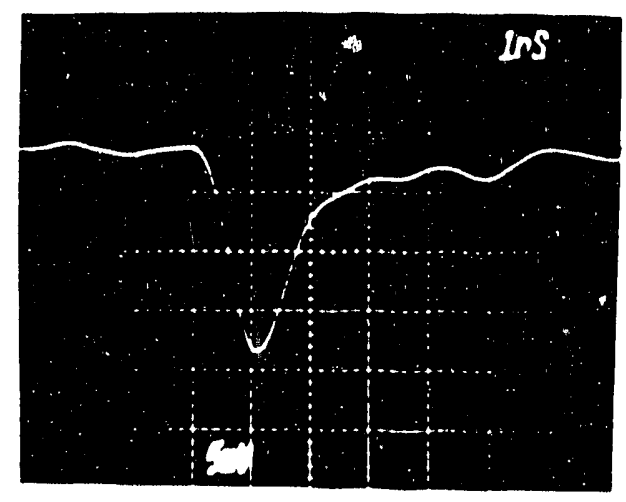

Fig. 3. All-optical modulation with $30 \mathrm{~nJ}, 0.571 \mu \mathrm{m}$ "pump" pulse.

The trace characteristics indicate subnanosecond decrease in transmisssion from the baseline level followed by nanosecond recovery. We esimate that the transmission at the minimum of the Gaussian pulse has been reduced by approximately $90 \%$.

In our next series of experiments, we changed both the wavelength and energy of the "pump" pulse, anil illuminated the integrated optical waveguide with $0.82 \mu \mathrm{m}$ laser pulses. The $0.82 \mu \mathrm{m}$ laser pulses have a penetration depth in gallium arsenide of approximately $5 \mu \mathrm{m}$; in contrast, $0.571 \mu \mathrm{m}$ pulses have a penetration depth of $0.2-0.3 \mu \mathrm{m}$. Thus, with short wavelength pulses, light absorption only occurs near the surface of the waveguide structure, while with long 
wavelength pulses, free carriers are generated throughout the waveguide. Fig. 4a shows an oscilloscope trace of the photodetector oulput when the waveguide is illuminated with $220 \mathrm{~nJ}, 0.82 \mu \mathrm{m}$ light pulses, and Fig. $4 \mathrm{~b}$ shows an oscilloscope trace when the waveguide is illuminated with $250 \mathrm{pJ}$ pulses (in both cases, the transmission is again reduced within the waveguide, but the oscilloscope has inverted the pulse). Fig. $4 \mathrm{~b}$ clearly indicates that light-with-light modulation is still detectable with $250 \mathrm{pJ}$ optical pulses, but the modulation depth is considerably reduced.

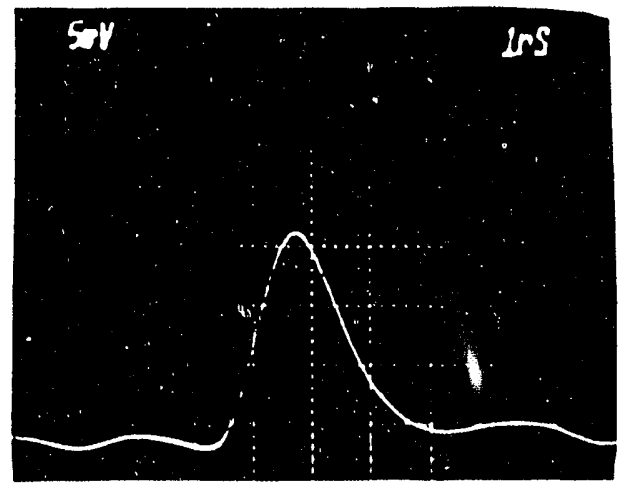

(a)

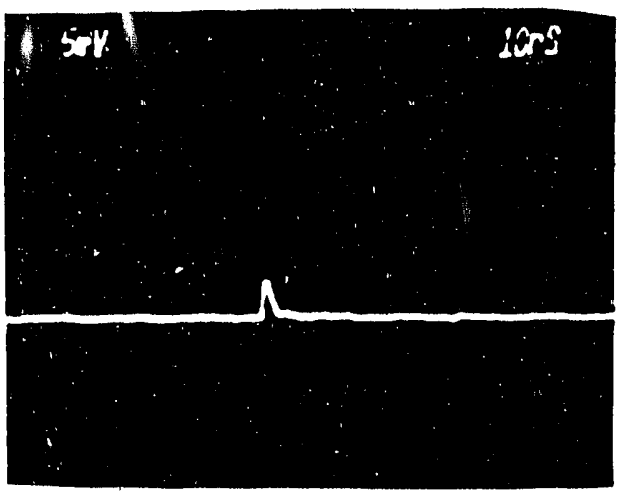

(b)

Figs. 4a-b. All-optical modulation with $220 \mathrm{~nJ}, 0.82 \mu \mathrm{m}$ "pump" pulses (a) and $250 \mathrm{pJ}, 0.82 \mu \mathrm{m}$ "pump" pulses (b).

Finally, we modified our experimental setup and observed modulation characteristics which are indicative of beam deflection, rather than beam absorption. The experimental setup is shown in Fig. 5.

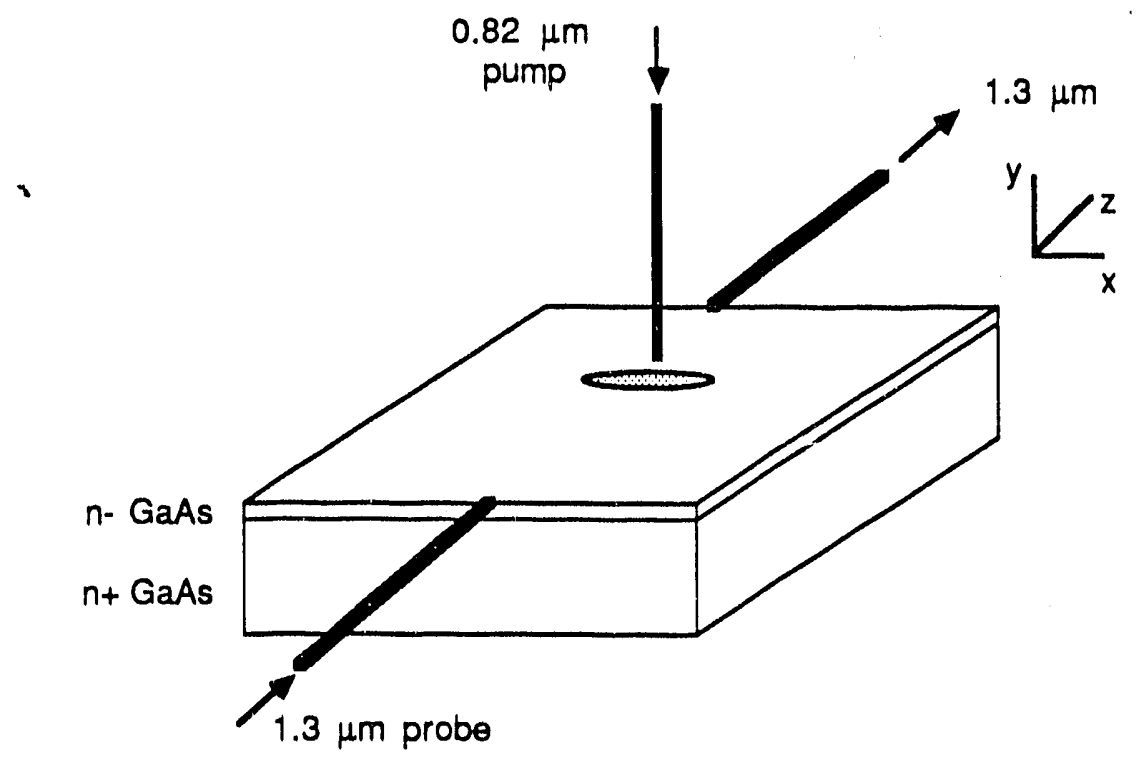

Fig. 5. Beam deflection experimental setup with GaAs planar waveguides.

We have replaced the ridge optical waveguide with a simple $n-/ n+G a A s$ optical waveguide. Light is again confined vertically to the n- layer; however, because there are no ridges, light is not confined horizontally. Again, light is coupled in and out of the waveguide with optical fibers, and an optical fiber is also used to provide the "pump" pulse. Figs. 6a-c show oscilloscope traces of the photodetector output from the optical fiber. First, we aligned the output 
fiber for maximum transmission $(x=0)$. As Fig. 6a indicates, carrier injection with the "pump" pulse yields a positive signal trace on the photodetector. Next, the output optical fiber was shifted laterally $15 \mu \mathrm{m}(\mathrm{x}=15 \mu \mathrm{m})$, and the carriers were again injected with the "pump" pulse. As Fig. $6 \mathrm{~b}$ indicates, the signal trace is first negative and then slightly positive. Finally, the output fiber was shifted laterally to $x=20 \mu \mathrm{m}$, and the experiment was repeated. As Fig. $6 c$ indicates, the signal trace is negative. Thus, the sign of the signal trace changes as the output fiber is shifted laterally. We attribute this result to creation of a negative free-carrier lens within the planar waveguide (5-6). Indeed, free-carrier injection can change both the absorption coefficient and the refractive index of the semiconductor; creation of a waveguide lens would tend to steer the guided beam, and our results are consistent with the theory that, if the fiber is slightly off-axis, the beam is deflected, first, into, and then past, and then back into the optical fiber (5). This behavior would thus explain the sign changes observed in Fig. 6a-c. Finally, we note that a ridge waveguide confines the guided light laterally. Thus, light absorption, rather than beam deflection, predominates in the experiments described in Figs. 14 .

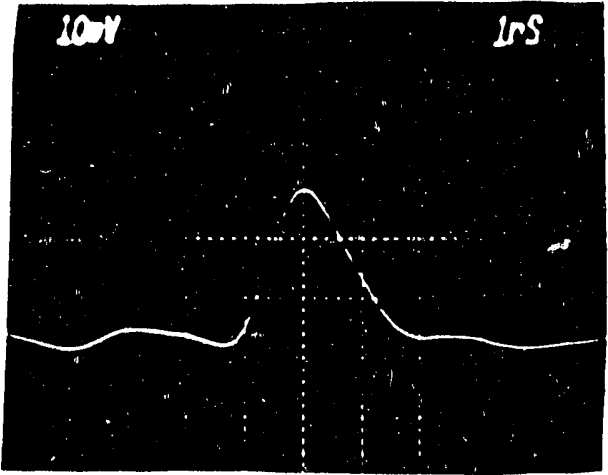

(a)

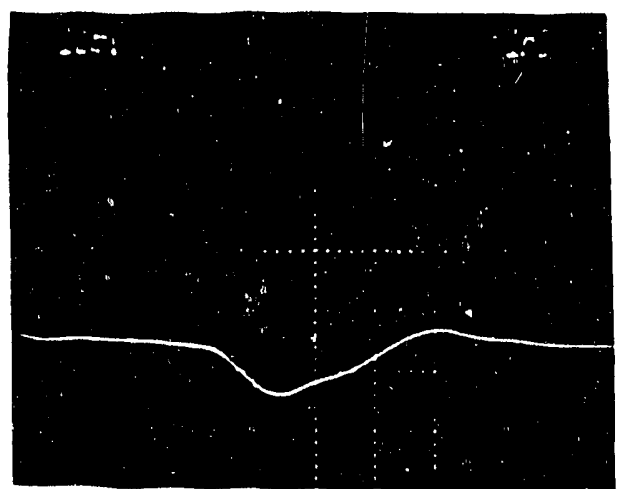

(b)

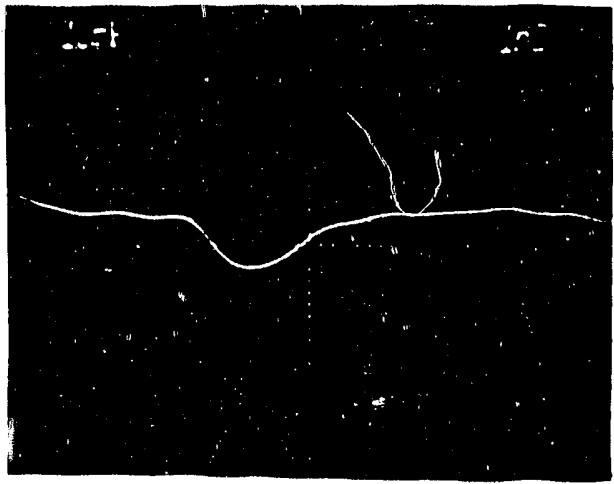

(c)

Figs. 6a-c. Beam deflection experiments with output optical fiber positioned at $x=0(a), x=15$ (b), and $x=20$ (c).

\section{CONCLIUSIONS}

In summary, we have studied all-optical modulation in gallium arsenide integrated optical waveguides. Modulation is due to injection of electron-hole pairs from a "pump" pulse with energy above the band-gap of the semiconductor material. Injection of electron-hole pairs, in turn, causes an increase in the absorption of a "probe"laser, thus modulating the light output. Subnanosecond, optical modulation with "pump" energies below $250 \mathrm{pJ}$ at $0.82 \mu \mathrm{m}$ has been demonstrated. The measured switching speed is limited not by our waveguide structures, but by our measurement technique. We have also observed behavior in planar waveguide structures which is indicative of beam deflection; that is, injection of free-carriers creates a negative lens within the waveguide structure, thus deflecting the beam. Our future work will be directed toward measuring the optical switching speed with greater accuracy. 


\section{ACKNOWLEDGMENTS}

The support and encouragement of J. Balch and M. Pocha is gratefully acknowleged. This work was performed under the auspices of the U.S. Department of Energy by Lawrence Livermore National Laboratory under Contract W-7405-Eng-48.

\section{REEERENCES}

1. M. J. Goodwin, "Nonlinear organic polymeric waveguides," Proceedings SPIE, Vol. 836, pp. 265-269 (1987).

2. P. Wa, P. Robson, J. David, G. Hill, P. Mistry, N. Pate, and J. Roberts, Electronics Letters, Vol. 22, pp. $1129-1130$ (1986).

3. J. Aitchison, J. Valera, A. WAlker, S. Ritchie, P. Rodgers, P. McIlroy, and G. Stegeman, "Whole-sample and localized induced-absorption optical bistability in GaAlAs waveguides," Applied Physics Letters, Vol. 51, pp. 561-563 (1987).

4. R. Normandin, D. Houghton, and M. Simard-Normandin, "Integrated all-optical modulator and logic gate for fiber optics systems," Broceedings of the Conference on Integrated and Guided-Wave Optics (TGWO), pp. $351-354$ (1988).

5. P. Colbourne and P. Jessop, "All-optical transients in a silicon waveguide," Broceedings SPIE, Vol. 994 (1988).

6. J. McFee, R. Nahory, M. Pollack, and R. Logan, "Beam deflection and amplitude modulation of $10.6 \mu \mathrm{m}$ guided waves by free-carrier injection in GaAs-AJGaAs heterostructures," Applied Physics Letters, Vol. 23, pp. 571-573 (1973). 

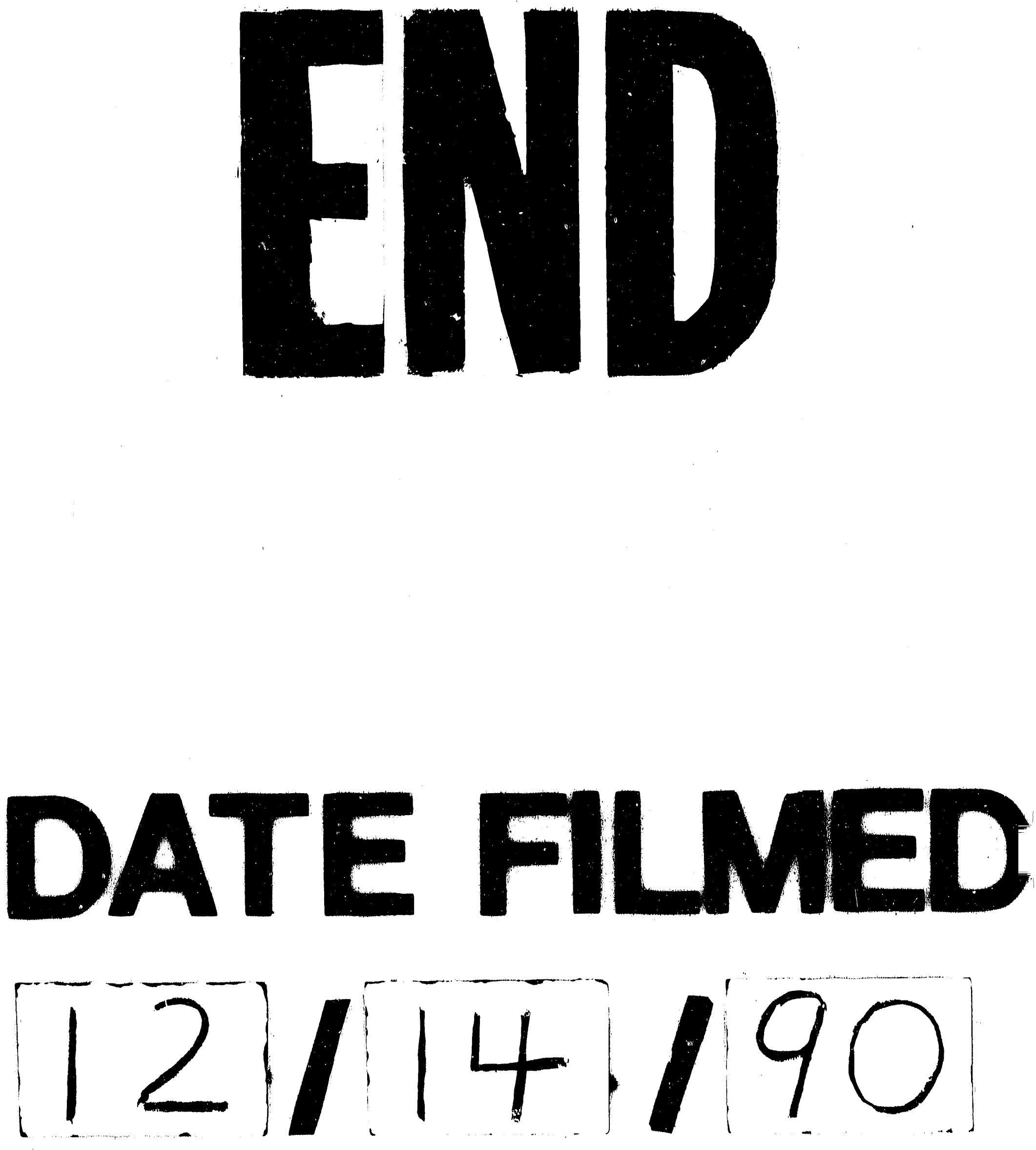
